\title{
FILOSOFIS KURIKULUM MATA PELAJARAN SEJARAH MASA ORDE LAMA
}

\author{
Zulkarnain \\ Prodi Pendidikan Sejarah, Fakultas Ilmu Sosial, Universitas Negeri Yogyakarta \\ zulkarnain@uny.ac.id
}

Abstract: $\quad$ Policymakers are often unaware of the effects of an important and strategic decision they make in the field of education, especially government policy in making changes to the curriculum. The importance of philosophy in curriculum development is based on his belief that education is a process of developing the potential of learners. The philosophy of curriculum development that is used as a foothold by the government in this case the ministry of education is very influential in determining the direction of the development of aspects related to education curriculum policy. These aspects include: objectives, materials, processes, and evaluations of learning outcomes. In curriculum development, Pancasila as the highest educational philosophy adopted from local and national religions and cultures needs to be embedded in the heart for every citizen, including the learners. In the old masses of philosophical and educational practices full of political contents and ideological doctrines, this is due to several things such as formally actually Indonesia only have national education law in 1950. Policy makers are more busy on matters relating with the constitution of the state, they forget that when Indonesian independence should be the main debate precisely at the level of educational philosophy. Therefore, five years after Indonesia's independence in 1950, then Indonesia has the Law of National Education System.

Abstrak: $\quad$ Para pengambil kebijakan sering kali tidak menyadari efek dari sebuah keputusan penting dan strategis yang diambilnya di bidang pendidikan, terutama kebijakan pemerintah dalam melakukan perubahan terhadap kurikulum. Arti pentingnya filosofi dalam suatu pengembangan kurikulum didasari atas keyakinannya bahwa pendidikan adalah sebuah proses pengembangan potensi peserta didik. Filosofi pengembangan kurikulum yang dijadikan pijakan oleh pemerintah dalam hal ini kementerian pendidikan sangat berpengaruh dalam menentukan arah perkembangan aspek-aspek yang berhubungan dengan kebijakan kurikulum pendidikan. Aspek-aspek tersebut meliputi: tujuan, materi, proses, dan evaluasi hasil belajar. Dalam pengembangan kurikulum, Pancasila sebagai filosofi pendidikan tertinggi yang diadopsi dari agama dan kebudayaan lokal serta nasional perlu terpatri dalam sanubari bagi setiap warga, termasuk di dalamnya para peserta didik. Pada massa orde lama filosofis dan praktik-praktik pendidikan sarat dengan muatan politis dan doktrin ideologis, hal ini disebabkan oleh beberapa hal diantaranya secara formal sebenarnya Indonesia baru mempuyai undang undang pendidikan nasional pada tahun 1950. Para pengambil kebijakan lebih banyak disibukkan pada hal-hal yang berhubungan dengan konstitusi kenegaraan, mereka lupa bahwa ketika Indonesia merdeka seharusnya perdebatan utama justru pada tataran filosofi pendidikan. Oleh karenanya, lima tahun setelah Indonesia merdeka tepatya pada tahun 1950, barulah Indonesia memiliki Undang-Undang Sistem Pendidikan nasional.

Kata Kunci: Nasionalisme, Patriotisme, toleransi, Filosofi Kurikulum,Sejarah, Orde Lama

\section{PENDAHULUAN}

Negara dan para pengambil kebijakan pendidikan sering kali tidak menyadari efek dari sebuah keputusan penting dan strategis yang diambilnya di bidang pendidikan, termasuk didalamnya kebijakan pemerintah dalam melakukan perubahan kebijakan pendidikan terutama hal-hal yang berhubungan dengan masalah filosofi kurikulum. Hal ini sering disepelekan, akan tetapi kalau dilihat efeknya yang ditimbulkan dalam jangka panjang dari sebuah kebijakan pendidikan yang keliru akan berakibat fatal bagi kelangsungan generasi di suatu negara. Karena indikasi berkualitas atau tidaknya suatu generasi salah satu tolak ukur yang digunakan adalah masalah pengelolaaan dan tanggung jawab negara terhadap masyarakatnya, yakni negara wajib mencerdaskan kehidupan bangsa melalui pengelolaan dunia pendidikan. Filosofi pengembangan kurikulum yang dijadikan pijakan oleh pemerintah dalam hal ini kementerian pendidikan ternyata sangat berpengaruh dan menentukan arah perkembangan aspek-aspek yang berhubungan dengan kebijakan kurikulum pendidikan. Aspek-aspek tersebut meliputi: tujuan, materi, proses, dan evaluasi hasil belajar.

Perubahan dan pengembangan kurikulum pendididikan pada umumnya menunjukan bahwa para pengambil kebijakan pendidikan di negeri ini lebih mempedulikan perubahan pada materi ajar dan proses tanpa memperhatikan masalah filosofinya. Oleh karenanya persoalan-persoalan yang menimpa pelajaran sejarah selama ini tidak lepas dari perubahan kurikulum, baik dalam bentuk dokumen maupun dalam bentuk proses belajar yang tidak disertai dengan perubahan filosofinya. Akibatnya perubahan kurikulum hanya pada label dan nama kurikulumnya tapi tidak membawa perubahan pada jiwa dan karakter peserta didik yang merupakan target atau sasaran dari sebuah perubahan. 
Di negara manapun, baik negara maju, negara berkembang, maupun negara miskin, mereka meyakini bahwa setiap peradaban bangsa selalu menempatkan ajaran filsafat yang komprehensif pada posisi dan status tertinggi dalam peradaban dan kebudayaan manusia. Ajaran filsafat dijadikan sebagai pandangan, pedoman hidup, atau ideologi dalam kehidupan berbangsa dan negara. Dengan demikian, kehidupan sosial, politik, ekonomi, pendidikan dan kebudayaaan, atas kesadaran nilai-nilai moral selalu bersumber dari ajaran filsafat. Ideologi atau ajaran filsafat pancasila sebagai ajaran filsafat tertinggi dalam kehidupan berbangsa dan bernegara di Indonesia dapat didefinisikan secara ringkas sebagai suatu refleksi kritis dan rasional tentang pancasila dalam pembangunan dunia pendidikan melalui pembaharuan kurikulum.

Pancasila sebagai filosofi pendidikan tertinggi yang diadopsi dari agama dan kebudayaan lokal serta nasional perlu terpatri dalam sanubari bagi setiap warga, termasuk di dalamnya para peserta didik. Proses penanaman nilai-nilai pancasila bisa dilakukan dengan beramacam cara mulai dari kehidupan keluarga, masyarakat, dan pendidikan.

Filosofi kurikulum massa awal kemerdekaaan lebih berorientasi pada penanaman sikap dan semangat patriotisme bertujuan untuk mengobarkan semangat kemerdekaan dan semangat juang generasi muda agar muncul keberanian dalam mempertahankan kemerdekaan Indonesia. Komitmen dan sikap yang selalu mengutamakan persatuan dan kesatuan bangsa Indonesia di atas kepentingan pribadi, kelompok, dan golongan merupakan karakteristik pribadi bangsa Indonesia. Karakter kebangsaan seseorang tercermin dalam sikap menempatkan persatuan, keselamatan, dan kepentingan bangsa di atas kepentingan pribadi atau golongan, rela berkorban untuk kepentingan bangsa dan negara, bangga sebagai bangsa Indonesia yang bertanah air Indonesia, memajukan pergaulan demi persatuan dan kesatuan bangsa yang ber-Bhineka Tungggal Ika.

\section{PEMBAHASAN}

Analisis Filosifis sering disebut juga sebagai filsafat analitis. Filsafat analitis tidak mengespresikan posisi filosofis khusus sebagaimana metateori melainkan sebagai disiplin yang dicirikan dengan suatu refleksi dengan kata-kata atau pernyataaan-pernyataan. Atas dasar inilah, maka tipe filsafat ini disebut dengan filsafat kritis, fisafat analitis atau filsafat metodologis (Brazinka, 1992: 171) Analisis filosofis merupakan salah satu pendekatan terhadap isu-isu di dalam filsafat pendidikan.

Ilmu pendidikan dan pendidikan di Indonesia memang menunjukkan perkembangan yang tidak selalu seiring sejalan. Dapat dikatakan bahwa praktik pendidikan yang dilakukan berjalan dalam keadaan "business as usual". Faktanya, pendidikan di Indonesia tetap ada, tetapi bersifat tradisional, tidak pernah dipersoalkan landasan teoritiknya. Artinya, ilmu pendidikan kurang dikembangkan di Indonesia.

Selama ini pendidikan di Indonesia berjalan tanpa ada refleksi yang sungguh-sungguh untuk landasan ilmiahfilosofisnya. Pendidikan di Indonesia dijalankan dengan lebih banyak meminjam (borrowing) atau mencangkok ide-ide (teori) dan praktik pendidikan dari luar tanpa memperhatikan konteks sosio-kultural masyarakat Indonesia dan nilainilai khas Indonesia. Pendidikan dengan cara mencangkok tampaknya lebih disukai oleh para pengambil kebijakan dan praktisi pendidikan di Indonesia. Memang, fenomena pencangkokan sistem, metode, model pendidikan merupakan gejala umum yang terjadi di mana-mana, bukan hanya Indonesia. Tetapi, bila tidak ditindaklanjuti dengan upaya "pribumisasi" berbagai teori dan praktik yang diambil tersebut, maka praktik pendidikan berjalan tanpa arah yang jelas. Oleh sebab itu, ilmu pendidikan yang berciri khas Indonesia perlu dikembangkan terus.

Ilmu pendidikan secara historis berkembang di Indonesia lebih muda dari praktik pendidikan itu sendiri. Sebagaimana dinyatakan oleh Tilaar bahwa praktik pendidikan di Indonesia dapat dilacak dari masa pra-Hindu, masa Hindu-Budha, masa Islam dan masa Kolonial. Pada masa sebelum kolonial, praktik pendidikan belum sistematis-ilmiah. Tetapi, pada masa colonial mulai ada teori-teori pendidikan yang sistematis dengan mengacu pada teori pedagogi di Belanda.

Setelah tahun 50-an orientasi pendidikan Indonesia beralih ke Amerika Serikat. Banyak sarjana kita yang lulus dari AS dengan kajian teori-teori pendidikan Amerika, khususnya yang bercorak filsafat pragmatism/eksperimentalisme dengan menggunakan metode kuantitatif. Kajian-kajian abstrak mulai ditinggalkan dan diganti dengan masalah-masalah praktis seperti metode mengajar. Tidak mengejutkan apabila Mochtar Buchori mengatakan bahwa saat ini pedagogi di Indonesia telah mati.

Selain itu, praktik-praktik pendidikan sarat dengan muatan politis. Pada masa awal kemerdekaaan sampai berakhirnya Orde Lama praktik pendidikan didasarkan pada pendidikan bersifat Eropasentris kolonialisme dan ideologis. Hal ini disebabkan oleh beberapa hal diantaranya secara formal sebenarnya Indonesia baru mempunyai undang undang pendidikan nasional pada tahun 1950. Para pengambil kebijakan lebih banyak disibukkan pada hal hal yang berhubungan dengan konstitusi kenegaraan, mereka lupa bahwa ketika Indonesia merdeka seharusnya perdebatan utama justru pada tataran filosofi pendidikan. Oleh karenanya, lima tahun setelah Indonesia merdeka tepatnya pada tahun 1950, barulah Indonesia memiliki Undang-Undang Sistem Pendidikan nasional (dokumen Kenegaraan UU NO. 4 Tahun 1950).

Walaupun belum mempunyai undang undang sistem pendidikan nasional, pada massa awal kemerdekaaan (1945-1950), filosofi pendidikan yang digunakan dalam rangka mencapai tujuan pendidikan adalah pendidikan Pancasila. Titik tekan filosopi pendidikan ini adalah pada aspek peningkatan kecerdasan kehidupan berbagsa dan bernegara serta mengupayakan penigkatan dan munculnya nasionalisme, patriotisme, dan penigkatan kesadaran nasional kebangsaan Indonesia. Hal ini bisa dipahami mengingat sebagai negara yang baru mendeklarasikan diri sebagai sebuah negara merdeka tentu ancaman dan rongrongan dari kaum penjajah yang ingin kembali menguasai Indonesia menjadi 
sesuatu yang mengkhawatirkan. Hal ini sesuai dengan filosofi pendidikan yang dikembangkan oleh tokoh pendidikan yang pada saat itu ditunjuk oleh Presiden Sukarno sebagai menteri PPK, yakni Ki Khadjar Dewantara.

Filosofi kurikulum massa awal kemerdekaaan lebih berorientasi pada penanaman sikap dan semangat patriotisme bertujuan untuk mengobarkan semangat kemerdekaan dan semangat juang generasi muda agar muncul keberanian dalam mempertahankan kemerdekaaan Indonesia. Komitemen dan sikap yang selalu mengutamakan persatuan dan kesatuan bangsa Indonesia di atas kepentingan pribadi, kelompok, dan golongan merupakan karakteristik pribadi bangsa Indonesia. Karakter kebangsaan seseorang tercermin dalam sikap menempatkan persatuan, keselamatan, dan kepentingan bangsa di atas kepentingan pribadi atau golongan, rela berkorban untuk kepentingan bangsa dan negara, bangga sebagai bangsa Indonesia yang bertanah air Indonesia, memajukan pergaulan demi persatuan dan kesatuan bangsa yang ber-Bhineka Tungggal Ika.

Dalam undang Undang pendidikan nasional tahun 1950 menyatakan bahwa : pendidikan dan pengajaran di Republik ini diutamakan sifat nasionalisme. Menindaklanjuti kebijakan tentang pendidikan nasional, Kementrian Pendidikan Pengajaran dan Kebudayaan Republik Indonesia pada tahun 1946 mengeluarkan suatu pedoman bagi guru-guru yang memuat sifat-sifat kemanusiaan dan kewarganegaraan sebagai dasar pengajaran dan pendidikan di negara Republik Indonesia yang pada dasarnya berintisarikan pada Pancasila. Pancasila dijadikan sebagai landasan Pilosofi dalam kehidupan berbangsa dan bernegara (UU.No.4 Tahun 1950).

Nilai-nilai yang terkandung dalam Pancasila yang dijadikan landasan dan filosofi dalam kehidupan bermasyarakat,berbangsa dan bernegara juga dikemukakan secara jelas oleh Presiden pertama Indonesia Sukarno. Selaku pelaku sejarah dan pelaku penggali Pancasila, suatu ketika pernah menyatakan bahwa Pancasila manakala diperas tuntas bisa berujud Eka Sila, yakni Gotong Royong. Politik bangsa dan negara waktu itu tengah berada pada situasi dan kondisi konfrontasi antara kekuatan komunis atheist dengan kekuatan agamis. Dari kalangan agamis keberatan dengan gagasan Bung Karno tersebut, karena memeras Ketuhanan Yang Maha Esa dimasukan menjadi bagian bagian gotong royong, karena dianggap sebagai langkah menyingkirkan agama dari kehidupan bernegara, sebagaimana dituntut oleh kaum komunis (Zamroni,2013-1-14).

Untuk mewujudkan gagasan dan ide besar Sukarno dibutuhkan kerja keras melalui semua pihak mulai dari pengambilkan kebijakan sampai pada pelaku di tatan bawah melalui sebuah strategi yang salah satunya adalah melalui pendidikan. Ada banyak konsep dan filosofi pendidikan yang bisa dijadikan acuaan dalam menanamkan nilai nilai pancasila salah satu konsep filosofinya adalah pendidikan populis berbasis budaya yang humanis religious. Pendidikan populis merupakan pendidikan yang mengedepankan keadilan dan kesetaraan dalam kehidupan sekolah dan proses pembelajaran, yang dilaksanakan dengan suasana kepengasuhan. Keadilan dan kesetaraan merupakan kondisi mutlak yang diperlukan untuk mewujudkan prestasi ekselens untuk semuanya. Ekselensi tidak sekedar diukur dengan standar seberapa jauh materi yang disajikan di kelas sudah dikuasai oleh peserta didik, melainkan juga perlu dievaluasi bagaimana manfaat keberadaan siswa dengan penguasaan ilmu terhadap orang lain. Lebih jauh lagi perlu juga dievaluasi seberapa jauh hasil pendidikan telah berdasarkan nilai-nilai kebudayaan Indonesia, dari Sabang sampai Merauke, sehingga pencapaian tujuan pendidikan bukan menjadi hal yang sukar (Zamroni, Resensi Pidato Dies Natalis 2013: 1-5 ).

Tujuan pendidikan nasional akan tercapai bila sejalan dengan filosofi yang telah ditentukan oleh para pengambil kebijakan seperti yang tertera dalam undang undang pendidikan nasional. Pada massa pemerintahan orde lama, filosofi pendidikan yang menjadi dasar pengembangan pendidikan nasional seperti yang tertuang Dalam UndangUndang Pendidikan No. 4 Tahun 1950, penjelasan umum No. 8 dan No. 9 dijelaskan bahwa pendidikan nasional memberi jaminan "keharusan untuk pendidikan kita atas kebudayaan nasional”. Kebijakan pemerintah dalam mengeluarkan UU No. 4 Tahun 1950 terhadap pendidikan nasional telah menempatkan kurikulum sejarah Indonesia pada posisi terhormat.

Bila pendapat para ahli tersebut diakaitkan dengan proses termasuk didalamnya pengajaran maka proses pengajaran sejarah Indonesia diharapkan mampu membalikkan situasi dan kondisi, dari masyarakat yang selama ini dibodohkan dengan pengajaran yang Eropa sentris, pro-kolonialisme dan lambat laun dapat mengikis budaya feodal yang merupakan warisan turun temurun sebagai peninggalan pemerintahan kolonial Belanda. Kurikulum sejarah diharapkan dapat diaplikasikan dalam sebuah pembelajaran yang mencerdaskan, serta dapat mewujudkan rasa nasionalisme generasi muda terhadap bangsa dan negara tercinta Indonesia. Pada masa penjajahan kolonialisme, baik Belanda maupun Jepang, Bangsa Indonesia merasa terasing dari sejarahnya sendiri. (UU No.4/1950 Tentang Kebijakan Nasional).

Setelah disahkannya Undang Undang No.4/1950, pemerintah mengeluarkan kebijakan baru dibidang pendidikan dan pengajaran yakni kurikulum 1952. Filosofi Kurikulum pendidikan 1952 mengarah kepada sistem pendidikan nasional,jal ini bisa dilihat dari tujuan pendidikan dan pengajaran seperti yang tertuang dalam UU No 12 Tahun 1954 Bab II Pasal 3 yakni membentuk manusia susila yang cakap dan warga negara yang demokratis serta bertanggung jawab kesejateraan masyarakat dan tanah air.

Selain tujuan pendidikan dalam UU NO.12 tahun 1954 juga dijelaskan dasar pendidikan dalam Bab III Pasal 4 yang berbunyi "pendidikan dan pengajaran berdasarkan atas asasasas yang termaktub dalam Pancasila, Undang-Undang Dasar RI dan atas kebudayaan kebangsaan Indonesia" (UU No 12 Tahun 1954). Pasal 7 menjabarkan tujuan setiap jenjang pendidikan yang dinyatakan pada Pasal 6 (pendidikan dan pengajaran taman kanak-kanak, pendidikan dan pengajaran rendah, pendidikan dan pengajaran menengah, pendidikan dan pengajaran tinggi) (UU No 12 Tahun 1954). 
UU No 121954 Pasal 7 secara eksplisit menyatakan tujuan jenjang tersebut berfokus pada kualitas manusia sebagai suatu pribadi. Untuk pendidikan menengah disebutkan "melanjutkan dan meluaskan pendidikan dan pengadjaran jang diberikan di sekolah rendah untuk mengembangkan citacita hidup serta membimbing kesanggupan murid sebagai anggota masyarakat, mendidik tenaga-tenaga ahli dalam pelbagai lapangan khusus sesuai dengan bakat masing-masing dan kebutuhan masjarakat dan/atau mempersiapkannya bagi pendidikan dan pengadjaran tinggi. Oleh karenanya dapat dikatakan bahwa kebijakan kurikulum pendidikan masa awal kemerdekaaan ketika menteri PPK dijabat oleh Ki Hadjar Dewantara sangat memperhatikan hal-hal yang berhubungan dengan filosofi pendidikan (UU No 12 Tahun 1954).

Pasal 7 Undang-Undang ini menunjukkan landasan filosofis pendidikan yang mendasar. Pertama, peserta didik ditempatkan sebagai subjek dan kepentingan mereka adalah fokus pendidikan yang utama. Kedua, pernyataan bahwa "menuntun tumbuhnya" dan "memberi kesempatan mengembangkan bakat dan minat" mereka adalah jelas memberikan tempat kepada peserta didik sebagai subjek dalam pendidikan dan sangat jelas berdasarkan pandangan pedagogi yang modern.

Berdasarkan kajian dokumen kurikulum Sejarah Indonesia mulai dari kementeriaan PPK yang di jabat oleh Ki Khadjar 1945 sampai lahirnya kurikulum sejarah 1964, filosofi pengembangan kurikulumnya lebih banyak mengarah pada pembahasan materi dan topik-topik yang berkaitan dengan periode pergerakan nasional. Kurikulum sejarah Indonesia lebih banyak megharapkan guru-guru sejarah agar menekankan pengajaran pada proses penanaman nilai-nilai nasionalisme, persatuan dan kesatuan di antara pluralisme atau keanekaragaman, toleransi dan saling menghargai. Bangsa Indonesia terdiri dari berbagai suku bangsa dan golongan. Tuhan telah menciptakan ini semua sebagai kekayaan dan kekuatan bangsa. Tuhan telah mengajarkan kepada kita bahwa diciptakan-Nya manusia bersuku-suku dan golongan-golongan agar kita saling mengenal dan menjalin tali silaturrahmi.

Kalau sudah demikian maka dengan didorongkan oleh keinginan luhur, yakni cita-cita ingin merdeka, maka terwujudlah persatuan dan kebersamaan. Usaha untuk mewujudkan persatuan ini berhasil dengan diikrarkannya sumpah pemuda yang menyatakan satu tanah air, satu bangsa: Indonesia, dan menjunjung bahasa persatuan yakni bahasa Indonesia. Sumpah Pemuda menjadi simbol kebersamaan dalam keanekaragaman dan sekaligus memberikan semangat untuk menggalang persatuan demi terwujudnya cita-cita kemerdekaan. Sumpah Pemuda adalah manifesto politik dan wujud nyata dari silaturakhim nasional., "Barang siapa yang mau menghidup-hidupkan silaturakhim maka akan dipanjangkan usianya dan diluaskan rezekinya." Inilah konsep nasionalisme yang dibimbing oleh nilai-nilai moral, nilai-nilai keagaaman yang oleh Toynbee dikatakan sebagai nasionalisme yang dibimbing oleh nilai-nilai universal agama-agama atas (higher religions) (Maarif, 2016).
Nasionalisme yang tidak dibimbing oleh nilai-nilai moral keagamaan, dapat terjebak pada dua kecenderungan. Pertama, nasionalisme yang sekuler, ekstrim berlebihan yang dapat melahirkan chauvinisme. Bentuk nasionalisme inilah yang dikritik oleh Toynbee, karena telah menyebabkan berkobarnya PD II yang menghancurkan peradaban manusia. Kedua, nasionalisme yang lemah sehingga menjadikan pendukungnya tidak memiliki kebanggaan nasional dan jati diri bangsa. Dalam konteks ini guru secara kreatif dapat membahas materi ini, misalnya dengan topik "Telaah Teks Sumpah Pemuda”. Seperti telah diterangkan di atas. Selanjutnya untuk membahas topik-topik yang terkait dengan materi ajar pada periode kemerdekaan, guru dapat mengaktualisasikan dan menanamkan nilai-nilai esensial yang relevan kepada para peserta didik, seperti nilai-nilai kemedekaan, kemandirian dan kebebasan yang bertanggung jawab, nilai demokrasi, patriotisme, masalah kepemimpinan dan keteladanan.

Agar lebih menumbuhkan kesadaran dan merangsang emosi peserta didik, guru sebagai fasilitator dan motivator dapat membelajarkan peserta didik untuk menelaah teks dan simbol-simbol kebangsaan. Misalnya mendiskusikan tentang teks Pembukaan UUD 1945 alinea 3, "Atas berkat rahmat Allah Yang Maha Kuasa dan dengan didorongkan oleh keinginan luhur, supaya berkehidupan kebangsaan yang bebas, maka rakyat Indonesa menyatakan dengan ini, kemerdekaannya", mendiskusikan makna Sang Saka Merah Putih, mengkaji baris-baris pada Lagu "Indonesia Raya". Kemudian juga bisa membahas biografi beberapa tokoh seperti Bung Karno, Bung Hatta, Sudirman, untuk mendapatkan nilai-nilai kepemimpinan dan keteladanan. Penanaman nilai nilai seperti ini merupakan representasi dari nilai-nilai filsafat pancasila yang secara subsatansi meliputi nilai persatuan (Pengamalan sila ketiga dari pancasila, atau sosionalisme, sosio demokrasi, gotong royong, monodualisme dan monopolaris, makhluk sosial, cinta kasih dan keadilan sosial).

Garis besar pikiran filosofis Sukarno mengenai Pancasila, diantaranya: Pancasila sebagai wawasan kebangsaan atau filsafat persatuan. Pidato Sukarno 1 Juni 1945 "Kita hendak mendirikan suatu negara 'semua buat semua' Pancasila berpangkal pada dasar pikiran kekeluargaan atau gotong royong, yang membuat Pancasila berpangkal pada dasar pikiran kekeluargan atau gotong royong, yang membuang pikiran individualisme sebagai sosionasionalisme dan sosiodemokrasi. Sosionasionalisme adalah nasionalisme yang berkemanusiaan suatu nasionalisme politik dan ekonomi, suatu nasionalisme yang bermaksud mencari keberesan politik dan keberesan ekonomi, keberesan negeri dan keberesan rezeki. Sosiodemokrasi adalah bukan demokrasi ala Revolusi Perancis, bukan revolusi ala Amerika. ala Inggris...tetapi ia adalah demokrasi sejati yang mencari keberesan politik dan keberesan ekonomi. Sosiodemokrasi adalah adalah demokrasi politik dan demokrasi ekonomi, Trilogi Bung Karno, yaitu "Berdaulat dan bebas dalam politik, berkepribadian dalam kebudayaan, dan berdikari dalam ekonomi”. Menurut Buya Syafii Ma’arif, Pancasila seharusnya menjadi arah Kurikulum pendidikan di Indonesia untuk memantapkan karakter manusia Indonesia. 
Dari perspektif historis terlihat jelas bagaimana peran pendiri republik dan peran para tokoh-tokoh pergerakan nasional yang pada akhirnya mereka bersepakat bahwa perlu landasan filosofi dalam kehidupan berbangsa dan bernegara. Landasan filosofis tersebut kemudian dicetuskan oleh Ir. Sukarno pada tanggal 1 Juni 1945 yang lebih dikenal dengan pancasila dan UUD 1945 (alinea ke IV). Ketentuan yuridis konstitusional tersebut dijadikan konstruksi hukum yang tentunya mengandung konsekuensi formal, fungsional, dan impratif. Pancasila dijadikan pijakan sebagai norma dasar dan norma tertinggi di dalam kehidupan berbangsa dan bernegara di negera republik Indonesia. Pancasila adalah ideologi negara dan ideologi bangsa Indonesia. Pancasila adalah identitas dan karakteristik bangsa atau keperibadian nasional yang perwujudannya secara melembaga sebagai sistem pancasila yang menjiwai setiap keperibadian bangsa, pandangan hidup (keyakinan bangsa) sistem kenegaraaan dan masyarakat Indonesia (Assidiqi, 2008).

Filosofi kurikulum Sejarah Indonesia mengalami sedikit kemunduran pada kurikulum Sejarah tahun 1964, filosofi kurikulum sejarah pada saat ini adalah manipol usdek. Hal ini secara tegas dijelaskan dalam instruksi Menteri Pendidikan dan Kebudayaaan No.2 tahun 1961. Filosofi pendidikan diwajibkan berdasarkan Pancasila dan Manipol (Manipesto politik) UUD 1945 yang materinya berorientasi pada sosialisme dalam perspektif Indonesia. Selain Ideologi Pancasila dan manipol usdek, dunia pendidikan termasuk kurikulum sejarah di instruksikan untuk mengkampayekan ideologi marhaenisme, ideologi ini di sosialisasikan oleh kelompok nasionalis.

Kondisi pendidikan pada saat itu bisa dikatakan melenceng dari roh filosofi sesungguhnya yakni pancasila dan UUD 1945, Akibatnya terlihat jelas dalam kegiatan pembelajaran dimana pendidikan kita kurang peduli terhadap persoalan kebangsaan dan kehidupan kebangsaan padahal kondisi politik saat itu sangat memanas dan kondisi negara diambang perpecahan

\section{SIMPULAN}

Secara umum dapat disimpulkan bahwa pengembangan kurikulum bila dilihat dari filosofi pendidikan adalah sebagai berikut:

Kurikulum pendidikan disemua jenjang pendidikan harsnya dikembangkan berdasarkan pada filosofi yang mengatakan bahwa proses pendidikan adalah upaya untuk mendekatkan apa yang dipelajari di sekolah dengan apa yang terjadi di masyarakat. Pengembangan kurikulum baik dalam bentuk menjadikan apa yang terjadi di masyarakat sebagai sumber konten kurikulum maupun mengembangkan potensi peserta didik sebagai agent of change dalam berpartisipasi meningkatkan kualitas kehidupan masyarakat. Manusia yang demokratik dalam sistem kehidupan bernegara, politik dan sosial adalah tujuan pendidikan yang harus menjadi kepedulian kurikulum.

Pada massa orde lama filosofis dan praktik-praktik pendidikan sarat dengan muatan politis dan doktrin ideologis Hal ini disebabkan oleh beberapa hal diantaranya secara formal sebenarnya Indonesia baru mempuyai undang undang pendidikan nasional pada tahun 1950. Para pengambil kebijakan lebih banyak disibukkan pada hal hal yang berhubungan dengan konstitusi kenegaraan, mereka lupa bahwa ketika Indonesia merdeka seharusnya perdebatan utama justru pada tataran filosofi pendidikan. Oleh karenanya, 5 tahun setelah Indonesia merdeka tepatya pada tahun 1950, barulah Indonesia memiliki Undang-Undang Sistem Pendidikan nasional.

\section{REFERENSI}

Agung, L. 2015. Telaah Kurikulum Sekolah Menengah Di Indonesia Sejak Kemerdekaan Hingga Reformasi. Yogyakarta: Ombak.

Dewey, J. (October 20, 1859) was an American philosopher, psychologist, and educational reformer whose ideas have been influential in education and social reform. Born: October 20, 1859, Burlington, Vermont, United States Died: June 1, 1952, New York City, New York, United States Education: University of Vermont (1879), Johns Hopkins University, University of Chicago Children: Gordon Dewey, Evelyn Dewey, Morris Dewey, More

Gutek, G.L. 1974. Philosophical Alternatives in Education. Ohio: Charles E. Merill Publishing Company.

Hasan, S. H. 2009. Evaluasi Kurikulum. Bandung: Remaja Rosdakarya.

Jackson, P.W. 1992. Handbook of Research On Curiculum (A Projeck of the American Educational Research Association). New york : Macmilan Publising Companny

Kementerian Penerangan Republik Indonesia. 1949. KenangKenangan Kongres Pendidikan Antar Indonesia Di Ibu Kota Republik Indonesia 15-20 Oktober 1949.

Maarif, A. S. 1995. "Historiografi dan pengajaran sejarah Indonesia”. Makalah Dalam Seminar Nasional Tentang "Demitologi Pemahaman Sejarah Masa Kini Dalam Rangka Pendewasaan Pengetahuan Sejarah Bangsa". Padang: FPIPS IKIP Padang.

Maarif, A. S. 1990. Islam dalam bingkai Ke-Indonesiaan dan Kemanusiaan.Jakarta : Maarif Institute.

Nasution. 1999. Kurikulum dan Pengajaran. Jakarta: Bumi Aksara.

Nasution. 2001. Asas-Asas Kurikulum. Jakarta: Bumi Aksara.

Oliva, P. F. 1992. Developing The Curriculum 3rd Edition. New York: Harper Collins Publishers.

Phillips, I. 2008. Teaching History Developing As A Reflective Secibdary Teacher. London: Sage Publication.

Pratt, D. 1980. Curriculum Design and Development. (New York: Harcourt Brace Javanovich Publishers.

Sjamsuddin, H dkk. 1993. Sejarah Pendidikan Di Indonesia Zaman Kemerdekaan (1945-1966). Jakarta: Departemen Pendidikan Dan Kebudayaan

Surat Keputusan Pemberhentian Ki Hadjar Dewantara Sebagai Menteri Pendidikan Tanggal 15 November 1945. Arsip Majelis Luhur Persatuan Taman Siswa. 


\section{Zulkarnaen}

Filosofis Kurikulum Mata Pelajaran Sejarah Masa Orde lama

Suryo, D. 2005. "Paradigma sejarah di Indonesia dan kurikulum sejarah", dalam Makalah Seminar Nasional dan Temu Alumni Program Studi Pendidikan Sejarah Program Pascasarjana Universitas Sebelas Maret Surakarta. Surakarta: PPS UNS.

Suyata. 2010. "Pemberdayaan sekolah". Makalah. Disampaikan pada workshop strategi pengembangan mutu sekolah bagi kepala sekolah dan pengawas sekolah tanggal 7 Agustus 2010 di PPs UNY

Telegram Kepada Ki Hadjar Dewantara Dari Menteri Pendidikan Untuk Segera Membentuk Pantia Penyelidik Pendidikan dan Pengajaran Tanggal 15 Febuari 1946. Arsip Majelis Luhur Persatuan Taman Siswa.
Tyler, R.W. 1973. Basic Principles of Curriculum and Instruction. London: Lowe and Brydone (Printers) Ltd

Undang-Undang Pokok Pendidikan dan Pengajaran No. 4 Tahun 1950 (UUPP). Arsip Ki Sarmidi Mangunsarkoro

Widja, I.G. 1989. Pengantar Ilmu Sejarah: Sejarah dalam Perspektif Pendidikan. Semarang: Satya Wacana.

Zamroni. 2006. "Demokrasi dan pendidikan dalam transisi", dalam buku kearifan sang profesor, bersuku-bangsa untuk saling mengenal. Yogyakarta: UNY Press

Zamroni. 2016. Refleksi Pendidikan dan Kebangsaan Setengah Abad: Kiprah A Malik 